\title{
Potentiometric Determination of Trace Amounts of Mercury (II) in Water Sample Using a New Modified Palm Shell Activated Carbon Paste Electrode Based on Kryptofix ${ }^{\circledR} 5^{*}$
}

\author{
Ahmed Abu Ismaiel, Mohamed Kheireddine Aroua, Rozita Yusoff \\ Chemical Engineering Department, University of Malaya, Kuala Lumpur, Malaysia \\ Email:mk_aroua@um.edu.my
}

Received August 2, 2012; revised September 14, 2012; accepted September 25, 2012

\begin{abstract}
A new modified palm shell activated carbon paste electrode based on 1,13-Bis(8-quinolyl)-1,4,7,10,13-pentaoxatridecane, 8,8-(1,4,7,10,13-Pentaoxatridecylene)-diquinoline (Kryptofix $\left.{ }^{\circledR} 5\right)$ and plasticizing agent was prepared and studied as $\mathrm{Hg}^{2+}$ selective electrode. The best performance was observed with the electrode composition having the ionophore-palm shell activated carbon-plasticizer composition 10\%:50\%:40\% with Nernstian response over the concentration range of $1.0 \times 10^{-8}-1.0 \times 10^{-2} \mathrm{M}$ with a slope of $42 \pm 1.5 \mathrm{mV}$ per decade of concentration. The detection limit as determined from the calibration plot is $1.0 \times 10^{-7} \mathrm{M}$. The proposed electrode shows good selectivity for $\mathrm{Hg}(\mathrm{II})$ with interfering ions. The response time of the electrode is fast $(\leq 10 \mathrm{~s})$, and can be used in the $\mathrm{pH}$ range of $3-11$. The electrode was used to determine mercury in drinking water.
\end{abstract}

Keywords: Palm Shell Activated Carbon; Kryptofix ${ }^{\circledR} 5$; Ion Selective Electrode; Mercury

\section{Introduction}

Contaminate water recourses by heavy metal is a serious worldwide environmental problem. Many metals such as mercury, cadmium, chromium and lead are known to be significantly toxic [1].

The importance of mercury to the environment cannot be overemphasized. From an environmental point of view, it is highly toxic, causing severe damage to the human central nervous system. Mercury concentrations in drinking, river or sea water are typically below $5 \mu \mathrm{g} \cdot \mathrm{L}^{-1}$, making it extremely difficult to measure using many techniques.

Therefore, measurement of free $\mathrm{Hg}(\mathrm{II})$ is important in assessing mercury toxicity and environmental monitoring. A number of methods, such as atomic absorption spectrometry (AAS) [2,3], inductively coupled plasma [4], $\mathrm{X}$-ray fluorescence spectrometry [5], anodic stripping voltammetry $[6,7]$ and potentiometry $[8,9]$ have been used for determination of mercury in the analytical samples. Many sensors for potentiometric determination of mercury(II) based on carbon paste CPE [10-16], polymeric membranes PVC [17-25] and coated wire electrodes [26-30] have been reported. However, these elec-

"University of Malaya, Postgraduate Research Grant (PPP). trodes are not very fruitful as they have either one, two, or in some cases, all the following problems: 1) a high detection limit; 2) a narrow working concentration rang; 3) a long response time; 4) serious interferences from various cations.

Potentiometric sensors based on ion-selective electrodes are especially suited for determination of several chemical species because they offer advantages such as selectivity, sensitivity, good precision, simplicity, and low cost.

Carbon-paste electrodes are considered a category of ion-selective electrodes that is composed of a carbon powder with a pasting liquid (an organic binder). The advantages of carbon paste electrodes such as ease of preparation and use, renewal of surface, chemical inertness, robustness, stability of response, low ohmic resistance, no need of internal solution and suitability for a variety of sensing and detection application drew the attention of researchers in recent years where these advantages were exploited for various measurements, including potentiometric measurements.

Palm shell activated carbon is a waste produced during palm kernel oil production, which is an important sector of Malaysia's economy. This material is easily available at low cost and has good electrochemical properties, such 
as good electrical conductivity, chemical and electrochemical inertness, favorable electrochemical behavior with analytes, low background current, and high surface area $[31,32]$.

In this work, the application of Kryptofix ${ }^{\circledR} 5$ as an ionophore shown in Figure 1 have been discussed for the detection of $\mathrm{Hg}(\mathrm{II})$ ions in drinking water samples. The sensor responds to $\mathrm{Hg}(\mathrm{II})$ ions. The recognition of small molecules in binding with heavy metals has gained importance in the field of research. The Kryptofix ${ }^{\mathbb{B}} 5$ has two donating nitrogen atoms and five oxygen atoms, low molecular weight and flexible structure were expected to act as a suitable ionophore in the preparation of carbon paste sensors for mercury ions of proper size and charge.

Structure of 1,13-Bis(8-quinolyl)-1,4,7,10,13-pentaoxatridecane, $8,8-(1,4,7,10,13$-Pentaoxatridecylene)-diqui-noline (Kryptofix ${ }^{\mathbb{}} 5$ ).

\section{Materials and Method}

\subsection{Materials}

All analytical reagent grade chemicals and distilled, deionized water were used for preparing all aqueous solutions. Commercial granular palm shell activated carbon (PSAC) was provided by Pacific Activated Carbon a local manufacturer in Johor Bahru, Malaysia. Activated carbon granules with particle size $<45 \mu \mathrm{m}$ were used throughhout the experiments. PSAC was washed with distilled water and was dried in an oven at $100^{\circ} \mathrm{C}$ for $24 \mathrm{~h}$. Metal salts as well as the plasticizers, bis(2-ethylhexyl)adipate (DOA), dioctyl phthalate (DOP), tris(2-ethylhexyl) phosphate (DOPh), dioctyl sebacate (DOS), butyl phosphate (BPh), dibutyl phosphate (DBPh), and tributyl phosphate (TBPh) were purchased from Merck. The ionophore Kryptofix ${ }^{\mathbb{B}} 5$ was purchased from Sigma-Aldrich.

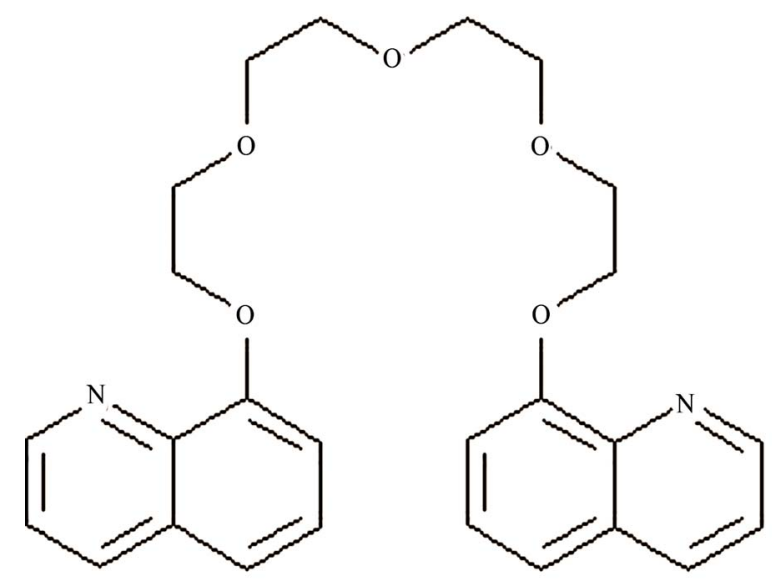

Figure 1. Structure of 1,13-Bis(8-quinolyl)-1,4,7,10,13-pentaoxatridecane, $8,8-(1,4,7,10,13-P e n t a 0 x a t r i d e c y l e n e)-d i-q u i-$ noline (Kryptofix $\left.{ }^{\circledR} 5\right)$.

\subsection{Experimental Equipments}

All potentiometric measurements were made with a $\mathrm{pH} /$ Ion meter (Metrohm-781, Germany) and $\mathrm{pH}$ Module (Metrohm-867) using proposed sensor in conjunction with a double junction $\mathrm{Ag} / \mathrm{AgCl}$ reference electrode. The temperature of the cell holder was maintained at $25^{\circ} \mathrm{C}$. The electrochemical cell used for this study as follow:

$\mathrm{Ag}(\mathrm{s}), \mathrm{AgCl}(\mathrm{s}), \mathrm{KCl}(3 \mathrm{M}$ sat.) sample solution modified palm shell activated carbon paste electrode.

Scanning electron micrographs (SEM) of the electrode surfaces were obtained by using scanning electron microscopy (AMETEK, advanced microanalysis solutions) at an accelerating voltage of $25 \mathrm{kV}$.

$\mathrm{Hg}$ (II) samples were analysed by Inductivity Couple Plasma ICP (PerkinElmer, model ICP optima 7000DV).

\subsection{Palm Shell Activated Carbon Paste Electrode Preparations and Potential Measurements}

Modified palm shell activated carbon paste was prepared by mixing of specified amount, as shown in Table 1, of palm shell activated carbon powder, Kryptofix ${ }^{\circledR} 5$ and plastecizer. The constituents were thoroughly hand mixed in a $50 \mathrm{~mm}$ petridish to produce a paste according to optimum value of ingredients, then the paste poured and packed into empty glassy carbon electrode $(5 \mathrm{~mm}$ dimeter), conected with the $\mathrm{pH} / \mathrm{Ion}$ meter by a thin copper wire to produce electrical contact. The composite surface was smoothed on a weighing paper until the surface showed shiny appearance and rinsed carefully with double-distilled water prior to each experiment.

The potentiometric measurements were conducted as follows. The modified carbon paste electrode was pleased in a stirred $50 \mathrm{ml} 0.1 \mathrm{M} \mathrm{Hg}^{2+}$ solution for a given period of time untill the potential reading became constant. The addition method was used for investigating the electrode response characteristics. Mercury salts standard solutions were added, so that the mercury concentration ranged between $10^{-8}$ and $10^{-1} \mathrm{M}$. Potential readings were recorded after each addition, when stable values had been obtained (usually after $30-60 \mathrm{~s}$ ). Potentiometric selectivity of this electrode towards different cations were calculated by using the matched potential method (MPM) [33]. In this method, the activity of $\mathrm{Hg}$ (II) was increased from $\mathrm{aA}=1.0 \times 10^{-5} \mathrm{M}$ (primary ion) to áA $=5.0 \times 10^{-5}$ $\mathrm{M}$, and the corresponding potential change $(\Delta \mathrm{E})$ were measured. Then a solution of an interfering ion $(\mathrm{aB})$ in the range $1.0 \times 10^{-1}-1.0 \times 10^{-2} \mathrm{M}$ was added to a new primary ion (áA) until the same potential change $(\Delta \mathrm{E})$ was recorded. The selectivity factor, $\mathrm{K}^{\mathrm{pot}} \mathrm{A}, \mathrm{B}$ for each interferent was calculated using the following: $\mathrm{K}^{\mathrm{pot}} \mathrm{A}, \mathrm{B}=$ $(\mathrm{a} A-\mathrm{aA}) / \mathrm{aB}$. 
Table 1. Palm shell activated carbon paste electrode compositions and general performance characteristics of mercury (II) ion selective electrode.

\begin{tabular}{|c|c|c|c|c|c|c|c|}
\hline \multirow{2}{*}{$\begin{array}{c}\text { Electrode } \\
\text { No. }\end{array}$} & \multicolumn{3}{|c|}{ Electrode composition (wt\%) } & \multicolumn{4}{|c|}{ Electrode characteristics } \\
\hline & Ionophore & PSAC & DOP & Slope $(\mathbf{m V})$ & Linear range (M) & $\begin{array}{c}\text { Detection limit } \\
\text { (M) }\end{array}$ & $\begin{array}{c}\text { Response time } \\
\text { (s) }\end{array}$ \\
\hline 1 & 0 & 55 & 45 & 55.52 & $10^{-2}-10^{-5}$ & $1 \times 10^{-4}$ & $15-20$ \\
\hline 2 & 0.2 & 55 & 44.8 & 61.86 & $10^{-2}-10^{-6}$ & $1 \times 10^{-6}$ & $15-20$ \\
\hline 3 & 0.5 & 55 & 44.5 & 59.55 & $10^{-2}-10^{-6}$ & $1 \times 10^{-6}$ & $\sim 15$ \\
\hline 4 & 1 & 54 & 45 & 54.07 & $10^{-2}-10^{-5}$ & $1 \times 10^{-5}$ & $\sim 15$ \\
\hline 5 & 2 & 54 & 44 & 53.73 & $10^{-2}-10^{-6}$ & $1 \times 10^{-6}$ & $\sim 15$ \\
\hline 6 & 4 & 54 & 42 & 62.08 & $10^{-2}-10^{-7}$ & $1 \times 10^{-6}$ & $\sim 15$ \\
\hline 7 & 5 & 50 & 45 & 61.46 & $10^{-2}-10^{-7}$ & $1 \times 10^{-7}$ & $\sim 10$ \\
\hline 8 & 6 & 52 & 42 & 64.46 & $10^{-2}-10^{-6}$ & $1 \times 10^{-7}$ & $\sim 15$ \\
\hline 9 & 8 & 50 & 42 & 55.03 & $10^{-2}-10^{-7}$ & $1 \times 10^{-7}$ & $\sim 15$ \\
\hline 10 & 9 & 47 & 44 & 36.12 & $10^{-2}-10^{-5}$ & $1 \times 10^{-6}$ & $\sim 10$ \\
\hline 11 & 10 & 50 & 40 & 42.41 & $10^{-2}-10^{-8}$ & $1 \times 10^{-7}$ & $<10$ \\
\hline 12 & 15 & 35 & 50 & 47.23 & $10^{-2}-10^{-6}$ & $1 \times 10^{-6}$ & $\sim 15$ \\
\hline 13 & 20 & 30 & 50 & 56.90 & $10^{-2}-10^{-6}$ & $1 \times 10^{-4}$ & $15-20$ \\
\hline 14 & 20 & 40 & 40 & 48.60 & $10^{-2}-10^{-5}$ & $1 \times 10^{-4}$ & $15-20$ \\
\hline
\end{tabular}

\section{Results and Discutions}

\subsection{Response of the Electrode}

The calibration for the $\mathrm{Hg}^{2+}$-selective electrode over a wide range of solution $\mathrm{Hg}^{2+}$ activities is shown in Figure 2. The slope of the calibration curve $(42.41 \mathrm{mV} / \mathrm{dec})$ closes to that predicted theoretically $(58.5 \mathrm{mV} / \mathrm{dec})$ by the Nernst equation, indicating that the electrode was sensitive to $\mathrm{Hg}^{2+}$ over a wide range of $\mathrm{Hg}^{2+}$ activities ( $10^{-7}$ fold).

In addition, the electrode showed a linear response over this range of activities, showing departure from linearity (i.e. loss of sensitivity) at activities lower than $10^{-7} \mathrm{M}$ $\mathrm{Hg}^{2+}$.

\subsection{Effect of Plasticizer}

The performance of an ISE electrode depends on its composition, especially, the plasticizer [34,35]. A plasticizer is added to ensure a non-interruption mobility of the ions in the paste. The proportion of plasticizer used must be optimized in order to minimize the electrical asymmetry of the paste, to keep the sensor as clean as possible, and to stop leaching to the aqueous phase [36]. It also determines the polarity as well as provides mechanical strength to the electrode. It is well established that the polarity and chemical structure of the plasticizer can have a significant influence on the sensitivity, stability,
Electrode Response

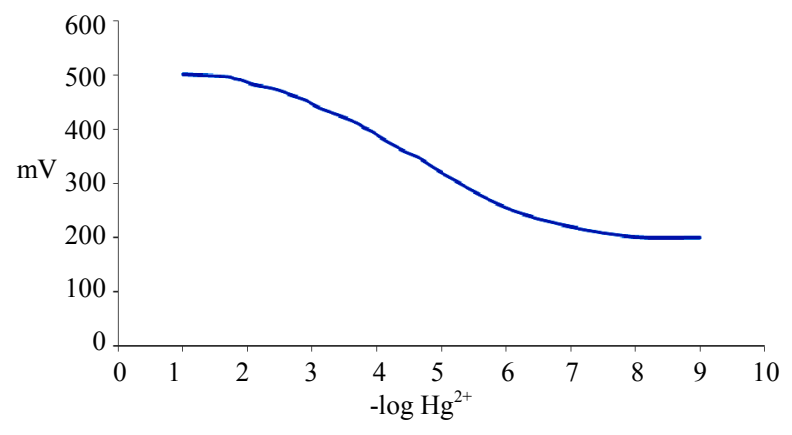

Figure 2. The calibration curve for a modified palm shell activated carbon paste electrode over a wide range of solution $\mathrm{Hg}^{2+}$ activities.

the selectivity and dynamic response range of ISEs [37]. Figure 3 shows the effect of various plasticizers on the performance of the mercury ion selective electrode. DOP was found to have the widest linear range of the electrode and the best detection limit among those tested.

The good performances are exhibited in Nernstian slope of $42.41 \mathrm{mV} /$ decade, linearity of concentration ranges between $1.0 \times 10^{-2}$ and $1.0 \times 10^{-8} \mathrm{M} \mathrm{Hg}^{2+}$, LOD at $1.0 \times 10^{-7} \mathrm{M}$. Average time required for every successsive measurement to reach stable readings with $\pm 2 \mathrm{mV}$ is less than 10s. There is no significant change of slope of Nernst plot over a period of 30 days. Other plasticizers, 


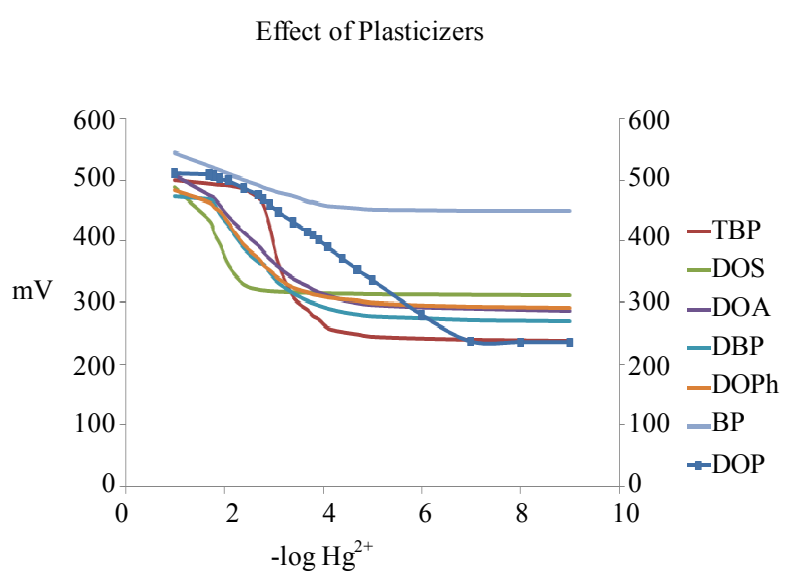

Figure 3. Effect of various plasticizers on the performance of the proposed mercury ion selective electrode.

i.e. $\mathrm{DOA}, \mathrm{DBP}, \mathrm{DOS}, \mathrm{TBP}, \mathrm{BP}$ and $\mathrm{DOPh}$ are unsuitable as they give sub-Nernstian slopes, slower and narrow linear concentration ranges.

\subsection{Effect of pH on Electrode Response}

The effect of $\mathrm{pH}$ of the test solutions $\left(1.0 \times 10^{-4} \mathrm{M}\right.$ and $1.0 \times 10^{-3} \mathrm{M} \mathrm{Hg}^{2+}$ ) on the electrode potential was investtigated by following the potential variation of the electrode over a $\mathrm{pH}$ range of $1-12$. The $\mathrm{pH}$ was adjusted by introducing small drops of hydrochloric acid (1 M) and/ or sodium hydroxide $(2 \mathrm{M})$ to the sample solution. Figure 4 shows the influence of $\mathrm{pH}$ on the potential response of the electrode e the sample solution on the potential response of the developed palm shell activated carbon paste electrode toward $1.0 \times 10^{-4} \mathrm{M}$ and $1.0 \times$ $10^{-3} \mathrm{M} \mathrm{Hg}^{2+}$. The experimental results show that the potential remained constant in the $\mathrm{pH}$ range of $3-11$, which can be used as the working $\mathrm{pH}$ range of the proposed electrode. However, outside this range, the electrode responses changed significantly. The diminished potential at $\mathrm{pH}>11$ was due to the interference of $\mathrm{OH}^{-}$ on the plain. The response at $\mathrm{pH}<3$ seemed ascribable to the competitive blinding of protons to the ligands on the electrode surface.

Under more acidic conditions, the ligand may be protonated and thereby losing its capacity to form a complex with the metal ions. When the $\mathrm{pH}$ is nearly neutral, the fundamental cation is $[\mathrm{HgOH}]^{+}$, which reacts with the ligand. The drift of potential values at $\mathrm{pH}$ is attributed to the formation of mercury(II) hydroxide [38,39].

\subsection{Potentiometric Selectivity Coefficients}

The influence of interfering ions on the response behaveior of an ion-selective electrode has usually been described in terms of selectivity coefficient. Potentiometric

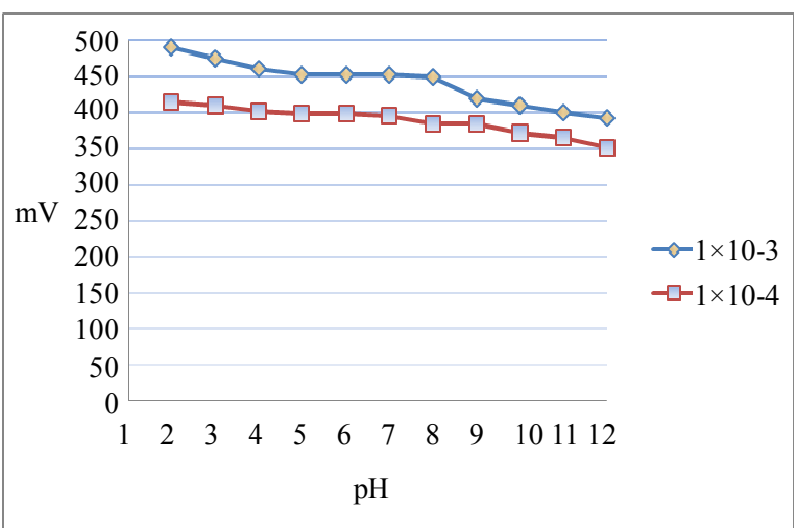

Figure 4. FEffect of $\mathrm{pH}$ on the potential response of $\mathbf{H g}^{2+}$ palm shell activated carbon paste electrode.

selectivity factors of the proposed mercury ion selective electrode over other ions was very important. The values of the selectivity coefficients $\mathrm{K}^{\text {pot }} \mathrm{A}, \mathrm{B}$ of the proposed electrodes towards different species (B) Table 2, were determined by the matched potential method.

As shown in Table 2, it can be observed, that the proposed electrodes exhibited better selectivity for $\mathrm{Hg}(\mathrm{II})$ ions.

Alkaline and alkaline earth metal ions did not interfere with the potentiometric response of the proposed electrodes. Some transition metal ions exhibited a light interference effect on the $\mathrm{Hg}^{2+}$ electrodes, which was more elevated in the proposed electrode.

\subsection{Response Time and Life Time}

The response time, defined as the time elapsed from the dipping of the electrode in the solution until the equilibrium potential was reached, varied from 5 to $10 \mathrm{~s}$ depending on the analyte concentration. The response time of the electrode was faster when the concentration was higher. The actual potential vs. time traces are shown in Figure 5. The sensing behavior of the membrane electrode did not depend on whether the potentials were recorded from low to high concentrations or vice versa.

The proposed electrode can be used for one or more months without any deterioration or change in the response of the electrode.

\subsection{Scanning Electron Microscopy Results}

Figure 6 compares the typical morphological features of palm shell activated carbon (PSAC) and palm shell activated carbon paste electrode based on Kryptofix ${ }^{\circledR} 5$ as ionophore (PSACPE) using FESEM. Pure palm shell activated carbon PSAC surface (Figure 6(a)) have porosity properties, smooth surfaces with long linear ridges and rough surfaces with oval ridges and micropores. Figure 6(b) shows a SEM image of PSACPE with more 
Table 2. Selectivity coefficients of various ions $\mathrm{B}$ with $\mathbf{H g}^{2+}$ activated carbon paste ion selective electrode based on Kryptofix $^{\circledR} 5$ using matched potential method (MPM).

\begin{tabular}{cccc}
\hline $\begin{array}{c}\text { Interferention, } \\
\mathbf{B}\end{array}$ & $\begin{array}{c}-\mathbf{l o g} \\
\mathbf{K}^{\mathbf{p o t}} \mathbf{A}, \mathbf{B}\end{array}$ & $\begin{array}{c}\text { Interferention, } \\
\mathbf{B}\end{array}$ & $\begin{array}{c}-\mathbf{l o g} \\
\mathbf{K}^{\mathbf{p o t}} \mathbf{A}, \mathbf{B}\end{array}$ \\
\hline $\mathrm{Cu}^{2+}$ & 0.86 & $\mathrm{Na}^{+}$ & 4.55 \\
$\mathrm{Cd}^{2+}$ & 3.81 & $\mathrm{~K}^{+}$ & 4.45 \\
$\mathrm{Ca}^{2+}$ & 4.50 & $\mathrm{Ni}^{2+}$ & 3.50 \\
$\mathrm{Mg}^{2+}$ & 4.15 & $\mathrm{Cr}^{3+}$ & 3.83 \\
$\mathrm{Zn}^{2+}$ & 3.55 & $\mathrm{Co}^{2+}$ & 3.48 \\
$\mathrm{Al}^{3+}$ & 2.80 & $\mathrm{~A}^{+\mathrm{g}}$ & 1.89 \\
$\mathrm{Fe}^{3+}$ & 2.45 & $\mathrm{~Pb}^{2+}$ & 2.55 \\
\hline
\end{tabular}

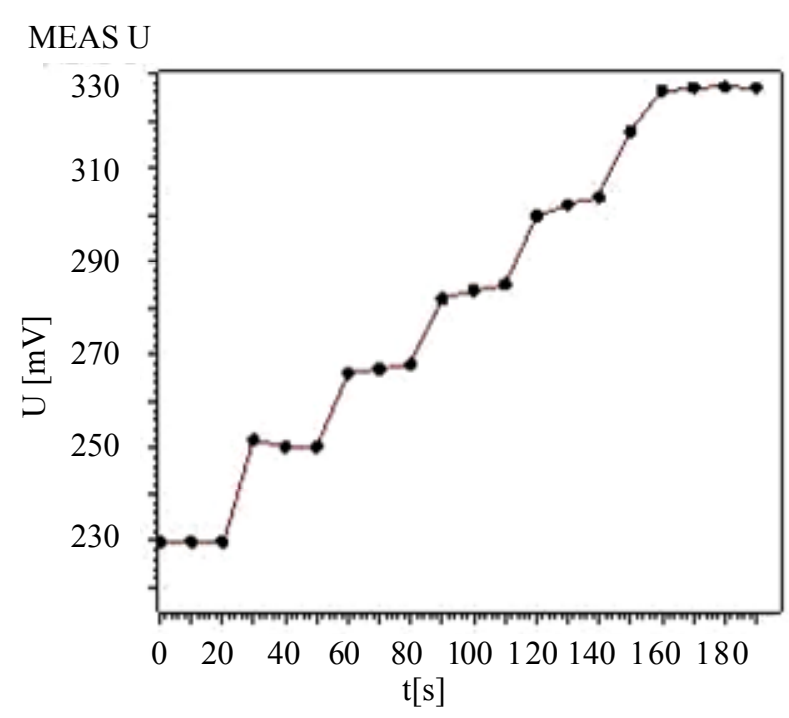

Figure 5. Response time of the palm shell activated carbon paste electrode for $\mathrm{Hg}^{2+}$ with changes of concentration from $1.0 \times 10^{-7} \mathrm{~mol} \cdot \mathrm{L}^{-1}$ to $1.0 \times 10^{-4} \mathrm{~mol} \cdot \mathrm{L}^{-1}$.

uniform surface topography and unique structure. Significant differences in the surface structure of PSACPE and PSACPE surface after it was dipped in $1 \times 10^{-4} \mathrm{M}$ $\mathrm{Hg}^{2+}$ solution for $30 \mathrm{~min}$ (Figure 6(c)) are observed. Scanning electron microscopy images indicate significant improvement in the microstructure of the proposed electrode.

Aggregates of white needles were observed in the surface (Figure 6(c)), which could be presumed to be complexes formed between the Kryptofix ${ }^{\circledR} 5$ and $\mathrm{Hg}^{2+}$ ions.

SEM images of (a) Pure PSAC, (b) PSAC paste electrode and (c) PSAC paste electrode surface after it was dipped in $1 \times 10^{-4} \mathrm{M} \mathrm{Hg}^{2+}$.

\subsection{Analytical Applications}

The proposed Hg-PSACPE was successfully applied for

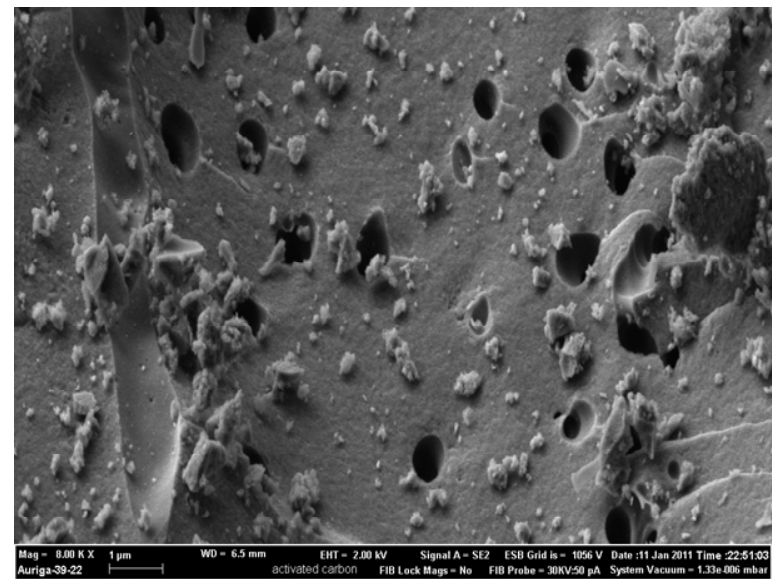

(a)

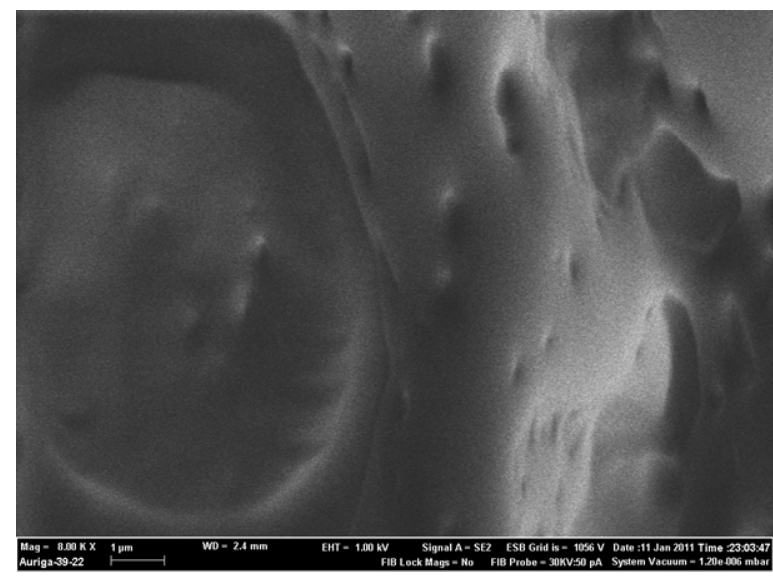

(b)

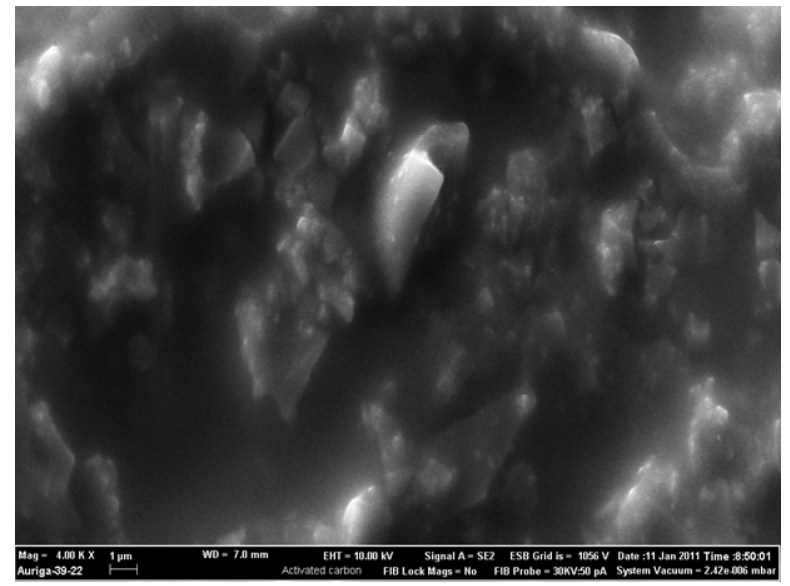

(c)

Figure 6. SEM images of (a) Pure PSAC; (b) PSAC paste electrode and (c) PSAC paste electrode surface after it was dipped in $1 \times 10^{-4} \mathrm{M} \mathrm{Hg}^{2+}$.

determination of $\mathrm{Hg}^{2+}$ in grandwater samples. The results were compared with data obtained by ICP (Table 3). The water samples were collected from Gaza ground water well (Palestine). The results indicate that the concentration of $\mathrm{Hg}(\mathrm{II})$ in groundwater samples are in good 
Table 3. Tpotentiometric determination of mercury(II) in some groundwater samples using $\mathrm{Hg}$ (II) electrode and ICP.

\begin{tabular}{ccccc}
\hline \multirow{2}{*}{ Sample $^{\mathbf{a}}$} & \multicolumn{4}{c}{$\mathbf{H g}(\mathrm{II})\left(\mathbf{m g} \cdot \mathbf{L}^{-\mathbf{1}}\right)^{\mathbf{b}}$} \\
\cline { 2 - 5 } & $\boldsymbol{P S A C P E}$ & $\boldsymbol{I C P}$ & $\boldsymbol{R S D} \%$ & Recovery\% \\
\hline$(1)$ & 1.363 & 2.038 & 3.36 & 95.4 \\
$(2)$ & 1.089 & 1.443 & 1.10 & 98.5 \\
$(3)$ & 1.151 & 1.499 & 4.81 & 93.4 \\
$(4)$ & 1.108 & 1.404 & 2.27 & 96.8 \\
\hline
\end{tabular}

${ }^{a}$ From some ground water wells in Gaza Strip. ${ }^{b}$ Mean data for three replicate measurements.

agreement with those obtained by ICP method. Thus the proposed electrode was highly accurate, precise, and reproducible and can be employed for quantification of $\mathrm{Hg}(\mathrm{II})$ in real samples

\section{Conclusion}

A new chemically modified palm shell activated carbon paste electrode (PSACPE) based on Kryptofix ${ }^{\circledR} 5$ as ionophore with simple preparation had fast response for detection of mercury ions. The electrode had wider working concentration range $\left(1 \times 10^{-8}\right.$ to $1.0 \times 10^{-2} \mathrm{~mol} \mathrm{~L}^{-1}$, low detection limit $\left(1 \times 10^{-7}\right)$ and low response time $(<10 \mathrm{~s})$.

\section{Acknowledgements}

The authors appreciate the financial support of the Islamic Development Bank, IDB Merit scholarship programme.

\section{REFERENCES}

[1] C. Xiong and C. Yao, "Synthesis, Characterization and Application of Triethylenetetramine Modified Polystyrene Resin in Removal of Mercury, Cadmium and Lead from Aqueous Solutions," Chemical Engineering Journal, Vol. 155, No. 3, 2009, pp. 844-850. doi:10.1016/j.cej.2009.09.009

[2] M. W. Hinds, "Determination of Mercury in Gold Bullion by Flame and Graphite Furnace Atomic Absorption Spectrometry," Spectrochimica Acta Part B: Atomic Spectroscopy, Vol. 53, No. 6-8, 1998, pp. 1063-1068. doi:10.1016/S0584-8547(98)00171-2

[3] P. Bermejo-Barrera, E. M. Verdura-Constenla, A. Moreda-Piñeiro, and A. Bermejo-Barrera, "Rapid Acid Leaching and Slurry Sampling Procedures for the Determination of Methyl-Mercury and Total Mercury in Human Hair by Electrothermal Atomic Absorption Spectrometry," Analytica Chimica Acta, Vol. 398, No. 2-3, 1999, pp. 263-272. doi:10.1016/S0003-2670(99)00453-5

[4] K. H. Lee, S. J. Jiang, and H. W. Liu, "Determination of Mercury in Urine by Electrothermal Vaporization Isotope Dilution Inductively Coupled Plasma Mass Spectrometry," Journal of Analytical Atomic Spectrometry, Vol. 13,
No. 11, 1998, pp. 1227-1231. doi:10.1039/a804857f

[5] L. Bennun and J. Gomez, "Determination of Mercury by Total-Reflection X-ray Fluorescence Using Amalgamation with Gold," Spectrochimica Acta Part B: Atomic Spectroscopy, Vol. 52, No. 8, 1997, pp. 1195-1200. doi:10.1016/S0584-8547(97)00003-7

[6] E. A. Viltchinskaia, L. L. Zeigman, D. M. Garcia, and P. F. Santos, "Simultaneous Determination of Mercury and Arsenic by Anodic Stripping Voltammetry," Electroanalysis, Vol. 9, No. 8, 1997, pp. 633-640. doi:10.1002/elan.1140090811

[7] J. Scaggs, D. D. Russell, M. W. Hill, and S. P. Duttagupta, "MEMS Sensor for Detecting Mercury at Ppb Levels," University/Government/Industry Microelectronics Symposium, 2001. Proceedings of the Fourteenth Biennial, 2001, p. 162.

[8] S. S. M. Hassan, M. B. Saleh, A. A. Abdel Gaber, R. A. H. Mekheimer, and N. A. Abdel Kream, "Novel Mercury (II) Ion-Selective Polymeric Membrane Sensor Based on Ethyl-2-benzoyl-2-phenylcarbamoyl Acetate," Talanta, Vol. 53, No. 2, 2000, pp. 285-293. doi:10.1016/S0039-9140(00)00445-8

[9] B. Rezaei, S. Meghdadi, and S. Bagherpour, "Cadmium Selective PVC-Membranes Sensor Based on 1,2-Bis (Quinoline-2-carboxamido)-4-chlorobenzene as a Neutral Carrier," Sensors Journal, IEEE, Vol. 8, No. 8, 2008, pp. 1469-1477. doi:10.1109/JSEN.2008.920719

[10] M. N. Abbas and G. A. E. Mostafa, "New TrIIodomercurate-Modified Carbon Paste Electrode for the Potentiometric Determination of Mercury," Analytica Chimica Acta, Vol. 478, No. 2, 2003, pp. 329-335. doi:10.1016/S0003-2670(02)01520-9

[11] M. H. Mashhadizadeh, et al., "A Novel Modified Carbon Paste Electrode for Potentiometric Determination of Mercury(II) Ion," Electroanalysis, Vol. 18, No. 22, 2006, pp. 2174-2179. doi:10.1002/elan.200603643

[12] J. Mehran, et al., "Potentiometric Detection of Mercury(II) Ions Using a Carbon Paste Electrode Modified with Substituted Thiourea-Functionalized Highly Ordered Nanoporous Silica," Analytical Sciences, Vol. 25, No. 6, 2009, pp. 789-794. doi:10.2116/analsci.25.789

[13] H. M. Abu-Shawish, "A Mercury(II) Selective Sensor Based on N,N'-Bis(salicylaldehyde)-phenylenediamine as Neutral Carrier for Potentiometric Analysis in Water Samples," Journal of Hazardous Materials, Vol. 167, No. 6, 2009, pp. 602-608. doi:10.1016/j.jhazmat.2009.01.018

[14] M. J. Gismera, J. R. Procopio, and M. T. Sevilla, "Characterization of Mercury-Humic Acids Interaction by Potentiometric Titration with a Modified Carbon Paste Mercury Sensor," Electroanalysis, Vol. 19, No. 10, 2007, pp. 1055-1061. doi:10.1002/elan.200603821

[15] G. Roa-Morales, M. T. Ramírez-Silva, R. L. González, L. Galicia, and M. Romero-Romo, "Electrochemical Characterization and Determination of Mercury Using Carbon Paste Electrodes Modified with Cyclodextrins," Electroanalysis, Vol. 17, No. 8, 2005, pp. 694-700. doi:10.1002/elan.200403099

[16] H. Zejli, et al., "Electrochemical Analysis of Mercury Using a Kryptofix Carbon-Paste Electrode," Analytical 
Letters, Vol. 40, No. 14, 2007, pp. 2788-2798. doi:10.1080/00032710701577906

[17] M. H. Mashhadizadeh and I. Sheikhshoaie, "Mercury(II) Ion-Selective Polymeric Membrane Sensor Based on a Recently Synthesized Schiff Base," Talanta, Vol. 60, No. 1, 2003, pp. 73-80. doi:10.1016/S0039-9140(03)00036-5

[18] X. Yu, et al., "Mercury(II)-Selective Polymeric Membrane Electrode Based on the 3-[4-(Dimethylamino)phenyl]-5-mecapto-1,5-diphenylpentanone," Sensors and Actuators B: Chemical, Vol. 123, No. 1, 2007, pp. 352-358. doi:10.1016/j.snb.2006.08.041

[19] V. K. Gupta, S. Chandra, and H. Lang, “A Highly Selective Mercury Electrode Based on a Diamine Donor Ligand," Talanta, Vol. 66, No. 3, 2005, pp. 575-580. doi:10.1016/j.talanta.2004.11.028

[20] G. Ye, Y. Chai, R. Yuan, and J. Dai, "A Mercury(II) Ion-Selective Electrode Based on N,N-Dimethyl-formamide-salicylacylhydrazone as a Neutral Carrier," Analytical Sciences, Vol. 22, No. 4, 2006, pp. 579-582. doi:10.2116/analsci.22.579

[21] X. Yang, D. Brynn Hibbert, and P. W. Alexander, "Flow Injection Potentiometry by Poly(Vinyl Chloride)-MemBrane Electrodes with Substituted Azacrown Ionophores for the Determination of Lead(II) and Mercury(II) Ions," Analytica Chimica Acta, Vol. 372, No. 3, 1998, pp. 387398. doi:10.1016/S0003-2670(98)00382-1

[22] V. K. Gupta, A. K. Singh, M. Al Khayat, and B. Gupta, "Neutral Carriers Based Polymeric Membrane Electrodes for Selective Determination of Mercury(II)," Analytica Chimica Acta, Vol. 590, No. 1, 2007, pp. 81-90. doi:10.1016/j.aca.2007.03.014

[23] M. K. Rofouei, M. Mohammadi, and M. B. Gholivand, "Mercury(II) Selective Membrane Electrode Based on 1,3-Bis(2-Methoxybenzene)Triazene," Materials Science and Engineering: C, Vol. 29, No. 7, 2009, pp. 2154-2159. doi:10.1016/j.msec.2009.04.017

[24] F. Bakhtiarzadeh and S. Ab Ghani, "An Ion Selective Electrode for Mercury(II) Based on Mercury(II) Complex of Poly(4-Vinyl Pyridine)," Journal of Electroanalytical Chemistry, Vol. 624, No. 1-2, 2008, pp. 139-143. doi:10.1016/j.jelechem.2008.08.007

[25] V. K. Gupta, S. Jain, and U. Khurana, "A PVC-Based Pentathia-15-Crown-5 Membrane Potentiometric Sensor for Mercury(II)," Electroanalysis, Vol. 9, No. 6, 1997, pp. 478-480. doi:10.1002/elan.1140090609

[26] R. W. Cattrall and C.-P. Pui, "Coated Wire Ion Selective Electrodes for the Determination of Mercury(II)," Analytical Chemistry, Vol. 48, No. 3, 1976, pp. 552-556. doi:10.1021/ac60367a033

[27] L. Perez-Marin, et al., "Mercury(II) Ion-Selective Electrode. Study of 1,3-Diphenylthiourea as Ionophore," Analyst, Vol. 125, No. 10, 2000, pp. 1787-1790. doi:10.1039/b003502p

[28] H. A. Arida, J. P. Kloock, and M. J. Schöning, "Novel Organic Membrane-Based Thin-Film Microsensors for the Determination of Heavy Metal Cations," Sensors, Vol.
6, No. 4, 2006, pp. 435-444. doi:10.3390/s6040435

[29] R. K. Mahajan, R. K. Puri, A. Marwaha, I. Kaur and M. P. Mahajan, "Highly Selective Potentiometric Determination of Mercury(II) Ions Using 1-Furan-2-Y1-4-(4-Nitrophenyl)-2-phenyl-5H-imidazole-3-oxide Based Membrane Electrodes," Journal of Hazardous Materials, Vol. 167, No. 1-3, 2009, pp. 237-243. doi:10.1016/j.jhazmat.2008.12.107

[30] M. Mazloum, M. K. Amini and I. Mohammadpoor-Baltork, "Mercury Selective Membrane Electrodes Using 2-Mercaptobenzimidazole, 2-Mercaptobenzothiazole, and Hexathiacyclooctadecane Carriers," Sensors and Actuators B: Chemical, Vol. 63, No. 1-2, 2000, pp. 80-85. doi:10.1016/S0925-4005(00)00300-2

[31] M. K. Aroua, S. P. P. Leong, L. Y. Teo, C. Y. Yin and W. M. A. W. Daud, "Real-Time Determination of Kinetics of Adsorption of Lead(II) onto Palm Shell-Based Activated Carbon Using Ion Selective Electrode," Bioresource Technology, Vol. 99, No. 13, 2008, pp. 5786-5792. doi:10.1016/j.biortech.2007.10.010

[32] G. Issabayeva, M. K. Aroua and N. M. Sulaiman, "Electrodeposition of Copper and Lead on Palm Shell Activated Carbon in a Flow-Through Electrolytic Cell," Desalination, Vol. 194, No. 1-3, 2006, pp. 192-201. doi:10.1016/j.desal.2005.09.029

[33] Y. Umezawa, P. Buhlmann, K. Umezawa, K. Tohda and S. Amemiya, "Potentiometric Selectivity Coefficients of Ion-Selective Electrodes, Part I, Inorganic Cations (IUPAC Technical Report)," Pure and Applied Chemistry, Vol. 72, No. 10, 2000, pp. 1851-2082. doi:10.1351/pac200072101851

[34] D. Jiménez, et al., "A New Chromo-Chemodosimeter Selective for Sulfide Anion," Journal of the American Chemical Society, Vol. 125, No. 30, 2003, pp. 9000-9001. doi:10.1021/ja0347336

[35] M. Vamvakaki and N. A. Chaniotakis, "Solid-Contact Ion-Selective Electrode with Stable Internal Electrode," Analytica Chimica Acta, Vol. 320, No. 1, 1996, pp. 53-61. doi:10.1016/0003-2670(95)00524-2

[36] J. Sánchez and M. d. Valle, "Determination of Anionic Surfactants Employing Potentiometric Sensors-A Review," Critical Reviews in Analytical Chemistry, Vol. 35, No. 1, 2005, pp. 15-29. doi:10.1080/10408340590947899

[37] V. K. Gupta, A. K. Singh, and B. Gupta, "Schiff Bases as Cadmium(II) Selective Ionophores in Polymeric Membrane Electrodes," Analytica Chimica Acta, Vol. 583, No. 2, 2007, pp. 340-348. doi:10.1016/j.aca.2006.10.039

[38] F. A. Cotton and G. Wilkinson, "Quimica Inorganica Avanzada," 4th Edition, Limusa, 1996.

[39] E. Lindner, K. Toth, and E. Pungor, "Lead-Selective Neutral Carrier Based Liquid Membrane Electrode," Analytical Chemistry, Vol. 56, No. 7, 1984, pp. 1127-1131. doi:10.1021/ac00271a016 